\title{
Enfrentando y previniendo las crisis financieras.
}

\section{Ricardo Ffrench-Davis}

La apertura de la cuenta de capitales puede traer importantes beneficios para la economía global. Sin embargo, también puede generar costos importantes. De hecho las finanzas internacionales han estado en el centro de las crisis económicas. La dimensión financiera jugó un papel central en la crisis de los años treinta y setenta, y en las crisis cambiaria de México en 1994 y de los países asiáticos ahora.

Las crisis recientes han hecho evidentes las profundas imperfecciones del mercado internacional de capitales y la gran vulnerabilidad de las economías en desarrollo a los choques provenientes de dicho mercado. El primero de estos fenómenos se refleja en la volatilidad que ha caracterizado al mercado durante las últimas décadas. La sucesión de oleadas de expansión excesiva y pánicos financieros indican que el mercado fluctúa más allá de lo que recomiendan los fundamentos de las economías.

Los costos de esta volatilidad son elevados para los paises en desarrollo. Las fases de auge de capitales tienden a desviar las variables macroeconómicas claves (como el tipo de cambio y los precios de los activos) de su equilibrio de largo plazo. El costo más importante de ello es que, si los flujos se revierten abruptamente, se pueden desencadenar crisis bancarias y financieras, que provocan grandes daños en los paises directamente afectados, y reducen la vitalidad del desarrollo económico mundial.

Hay creciente necesidad de encontrar nuevos arreglos institucionales que minimicen los riesgos de que ocurran crisis cambiarias y' financieras. Este es, por lo tanto, un momento oportuno para repensar el ordenamiento financiero internacional $y$, por el contrario, uno poco oportuno para una liberalización adicional de dicho mercado.

Más allá de la necesidad de mejorar el manejo de las crisis mismas, aqui se destacan dos elementos. El primero es que el centro de atención debe ser la gestión de las bonanzas y no de las crisis, ya que éstas suelen ser el resultado de bonanzas mal manejadas. El segundo es que la ausencia de un marco regulatorio 
apropiado a nivel internacional justifica la adopción de medidas nacionales que estén orientadas al objetivo de controlar las bonanzas que las autoridades consideren insostenibles. Cabe destacar los sistemas de encajes a flujos externos que han utilizado con éxito Colombia y Chile. En el texto se examinan propuestas en los planos nacional e internacional.

\section{Introducción}

La apertura de la cuenta de capitales puede traer importantes beneficios para la economía global. En particular, permite una movilización más fluida de fondos desde los países con abundancia de capital hacia aquellos con escasez. Ello mejora la eficiencia de la asignación de recursos, elevando su productividad. Permite a los países en desarrollo obtener ahorro externo que complemente el ahorro interno, y así alcanzar niveles de inversión y de crecimiento mayores. Sin embargo, la integración a los mercados internacionales de capitales también puede tener costos importantes, si no se hace reconociendo pragmáticamente la especificidad y capacidad de respuesta de diferentes mercados, con diversos grados de desarrollo.

Las finanzas han estado en el centro de las crisis económicas de alcance internacional. La dimensión financiera jugó un papel central en la crisis de Ios años treinta, y en la crisis de la deuda de países en desarrollo de los años setenta. En este decenio, le ha correspondido un papel también central en la crisis cambiaria de México y en la actual de los países asiáticos. Las estimaciones del costo de esta crisis para los países asiáticos más directamente afectados son cuantiosas. Se trata, además, de cinco países cuya expansión de las exportaciones se haya entre las diez más dinámicas del mundo en los años noventa. Pero el impacto también alcanza significación para el mundo en su conjunto. En efecto, las proyecciones de crecimiento del PIB mundial realizadas después de la crisis asiática, en comparación con las realizadas antes, se han reducido entre 0.3 y 0.8 puntos para 1998. Esta cifra parece pequeña. Sin embargo, como se aplica a todo el PIB mundial, representa en promedio una elevada cantidad. Así, medio punto representaría US\$ $\$ 150.000$ millones de producción perdida en sólo el año 1998. 


\section{La volatilidad del actual sistema financiero internacional}

Las crisis recientes han hecho evidentes dos aspectos: las enormes imperfecciones del mercado internacional de capitales y la gran vulnerabilidad de las economías en desarrollo a los choques provenientes de dicho mercado. El primero de estos fenómenos se refleja en la volatilidad que ha caracterizado al mercado durante las últimas décadas. La sucesión de oleadas de expansión excesiva y pánicos financieros indican que el mercado tiende a crecer, primero, y a contraerse, después, más allá de lo que recomiendan en uno y otro caso, los factores fundamentales de las economías. Esta volatilidad tiene que ver con la naturaleza de operaciones financieras, pero también con la ausencia de instituciones apropiadas para regular un mercado financiero tan sofisticado pero inestable. Refleja, en efecto, insuficiencias en la coordinación macroeconómica entre las naciones más influyentes en los mercados mundiales, y limitaciones de la institucionalidad internacional, en los campos regulatorio, de coordinación de políticas y de información. No existe ninguna institución internacional que contribuya a evitar que se desarrollen bonanzas financieras insostenibles y el Fondo Monetario Internacional posee sólo una capacidad limitada para manejar las crisis subsiguientes. Estas insuficiencias no son compatibles con un proceso de globalización balanceado y eficiente.

Por su parte, las agencias calificadoras de riesgo, que constituyen una de las fuentes más influyentes de generación de información a los mercados, tienden a acentuar estas tendencias, como lo demuestra un reciente estudio del Centro de Desarrollo de la OCDE. Estas agencias, así como los operadores financieros, cumplen un papel microeconómico muy funcional para el desarrollo. Sin embargo, y quizás sin quererlo, juegan también un rol macroeconómico. Las calificaciones de las agencias y sus expectativas, comunicadas profusamente en la prensa económica, contribuyen a reforzar el flujo financiero hacia los países "exitosos", contribuyendo a sostener un proceso que parece muy eficiente y sostenible (con buenas utilidades y garantías crediticias apoyadas en altos precios de activos y bajos precios de pasivos en dólares), pero que en realidad está generando burbujas, que más tarde o temprano explotan. Entonces todas estas señales, entre ellas las calificaciones de riesgo, se revierten, lo que acentúa la caída y profundiza la crisis.

Desde el punto de vista de los países en desarrollo, los costos de esta 
volatilidad son elevados. Las fases de auge de capitales tienden a alejar las variables macroeconómicas claves (como el tipo de cambio y los precios de los activos) de su equilibrio de largo plazo. El costo más importante de ellos es que, si los flujos caen o, aún peor, se revierten abruptamente, se pueden desencadenar crisis bancarias y financieras, que provocan conmoción y grandes daños en los países directamente afectados. Las incertidumbres resultantes afectan, en particular, la vitalidad del proceso de desarrollo.

En principio, los países receptores de fondos tienen cierto espacio para definir sus políticas nacionales respecto de los flujos de capitales. Pueden admitir pasivamente la transmisión hacia sus mercados internos de los cambios externos, o pueden tratar de moderarlos o graduarlos en el tiempo, afectar la composición de los flujos y suavizar sus efectos sobre el tipo de cambio y la demanda agregada. La práctica predominante ha sido que los países receptores han sido estimulados y elogiados por adoptar, en la etapa de auge de influjos, una política de aceptación de todos los recursos financieros que se les ofrezcan. Con las presiones a abrir la cuenta de capitales, aún en ausencia de regulaciones prudenciales adecuadas, han sido empujados al desequilibrio que luego provoca la crisis. Las recriminaciones han venido después, en los períodos de egresos masivos, por haberse endeudado en exceso. Hay una evidente contradicción entre ambas actitudes. Ello se refleja, además, en que se gasta más energía en resolver las crisis que en prevenirlas.

Los costos de la inestabilidad son elevados para la comunidad internacional y para los mercados de capitales internacionales, pero sobre todo para el desarrollo estable de la economía mundial. Hay consenso creciente sobre la necesidad de encontrar nuevos arreglos institucionales que minimicen los riesgos de que ocurran crisis cambiarías y financieras y, por esta vía, fortalezcan los beneficios de los flujos de capitales.

\section{Momento para decisiones oportunas y que sirvan al conjunto}

Este es, por lo tanto, un momento oportuno para repensar el ordenamiento financiero internacional y, por el contrario, uno poco oportuno para analizar una liberalización adicional de dicho mercado, tema que se encuentra en 
discusión en torno al cambio de los estatutos del FMI para otorgarle un mandato en materia de convertibilidad de la cuenta de capitales.

Más allá de la necesidad de mejorar el manejo de las crisis mismas, y de introducir mayor pragmatismo a las políticas de ajuste, queremos destacar dos elementos. El primero es que el centro de atención debe ser el manejo de las bonanzas y no de las crisis, ya que éstas son, en muchos sentidos, el resultado inevitable de bonanzas mal manejadas. Este es un punto de vista esencial, ya que, de alguna manera, las instituciones existentes, en especial el FMI, han sido diseñadas para manejar las crisis y carecemos, por el contrario, de instrumentos apropiados para alertar sobre la gestación de desequilibrios y, así, prevenir a tiempo el desarrollo de bonanzas insostenibles. El segundo es que la ausencia de un marco regulatorio apropiado a nivel internacional justifica la adopción de medidas nacionales que estén orientadas precisamente al objetivo de controlar las bonanzas que las autoridades consideren insostenibles. Cabe destacar, en especial, los sistemas de encajes a pasivos externos que han venido utilizando con éxito Colombia y Chile.

El exceso de atención en el manejo de las crisis ignora, en realidad, un hecho que debería ser evidente: que los grados de libertad de las autoridades son mayores en las bonanzas que en las crisis. Una bonanza caracterizada por la expansión excesiva del gasto público y privado acentúa el ciclo, generando inevitablemente un ajuste recesivo posterior, cuya severidad es función del exceso de gasto precedente. Así, un aumento insostenible del gasto público, basado en ingresos tributarios transitorios y el acceso extraordinario al crédito externo, da lugar a un severo ajuste posterior. Un endeudamiento excesivo del sector privado, basado en una subestimación de los riesgos asociados a un stock creciente de pasivos externos, da lugar a una profunda contracción crediticia posterior, acompañada generalmente por un deterioro de la cartera bancaria que, si es suficientemente intensa, puede generar pérdidas equivalentes a elevadas proporciones del PIB. Una sobrevaluación de la moneda, basada en ingresos de capital transitorios o unos precios extraordinarios de los productos de exportación, da lugar a una fuerte presión sobre la tasa de cambio o las tasas de interés, una vez que dichos fenómenos transitorios desaparecen.

Una vez que la situación comienza a deteriorarse y aún más cuando estalla una crisis, las autoridades económicas tienen pocas opciones, y dichas opciones 
tienden a traer efectos negativos sobre el crecimiento (como es el alza de las tasas de interés, el corte del gasto público y/o el desplome de las monedas nacionales). Por ello, la clave para el éxito en el manejo de la volatilidad es la prudencia y el uso de un instrumental apropiado durante las bonanzas.

\section{Una propuesta para desarrollo financiero con estabilidad sostenible}

El reto fundamental para el manejo de la vulnerabilidad externa es diseñar instrumentos apropiados para administrar las bonanzas a nivel internacional y doméstico.

\section{A.-Arreglos financieros nacionales}

Este tipo de instrumentos debe incluir, en primer término, mecanismos para esterilizar ingresos fiscales transitorios. Las experiencias parciales que se han venido acumulando con fondos de estabilización de ingresos fiscales provenientes del manejo de productos básicos deben generalizarse a la gestión de ingresos tributarios transitorios. Esto indica, por lo demás, que los objetivos fiscales deben fijarse, no en función del déficit fiscal corriente, sino de alguna medida del déficit estructural, como acontece en los países de la OCDE. Más aún, muchos países pueden encontrar que es atractivo compensar total o parcialmente las tendencias de corto plazo del gasto privado (tanto expansivas como contractivas), con movimientos en sentido compensador del gasto o del ingreso público.

En relación a la política monetaria, su habilidad de jugar un rol contracíclico está bastante limitada ante grandes flujos de capitales. Sin embargo, es posible introducir medidas que le den mayor autonomía para hacerlo. Una de estas medidas es el uso de mecanismos para desincentivar el ingreso excesivo de capitales de corto plazo, como son los encajes en Colombia y Chile y los impuestos variables en Brasil. A pesar de sus imperfecciones, existe consenso creciente que dichos mecanismos juegan un papel positivo porque logran desincentivar ingresos excesivos de flujos, disminuyendo además la proporción de flujos de corto plazo. Lo último, 
en particular, hace al país menos vulnerable a crisis cambiarias. E1 desincentivo a ingresos excesivos de flujos de capital contribuye, además, a disminuir la presión hacia un fortalecimiento excesivo de la moneda nacional; esto ayuda a mantener la competitividad y el dinamismo de las exportaciones, así como a controlar la magnitud del déficit en la cuenta corriente de la balanza de pagos.

Como se ha señalado reiteradamente, una regulación prudencial fuerte del sistema financiero es una de las claves fundamentales para evitar que los intermediarios asuman riesgos inmanejables durante los períodos de bonanza. Por ello, la apertura financiera de los países en desarrollo debe estar estrictamente condicionada a la existencia previa de una fuerte regulación prudencial. Por otra parte, no sólo la política macroeconómica debe adecuarse al nuevo contexto de volatilidad. También necesita hacerlo la regulación y supervisión de los sistemas financieros domésticos, que deben incorporar mayores elementos anticíclicos o estabilizadores del ciclo.

En este sentido, deseamos destacar tres elementos posibles. El primero es el establecimiento de requisitos de capital activos para los bancos más elevados que los de Basilea, para tomar en cuenta que potenciales crisis cambiarias en países latinoamericanos pueden tener un efecto particularmente negativo en los activos de los bancos. El segundo es hacer más estricta la supervisión prudencial de créditos externos de corto plazo, particularmente aquéllos intermediarios a través del sistema bancario nacional y que no estén vinculados a operaciones comerciales. El tercero es poner límites superiores al precio de referencia de los activos usados como garantías para préstamos u otras operaciones financieras, cuando el valor de tales activos -por ejemplo activos inmobiliarios y las accionesfluctúa mucho en los ciclos de auge y recesión.

\section{B.- Arreglos financieros internacionales}

Si bien son importantes las medidas que pueden tomar los países emergentes para manejar mejor la volatilidad financiera, su margen de acción es relativamente restringido. Por ello, parece cada vez más claro que estas medidas a nivel de países receptores de flujos deben ser complementadas por modificaciones en los arreglos financieros internacionales. 
En particular, hay cada vez más consenso en que los mercados internacionales de capital adolecen en ciertas circunstancias de importantes imperfecciones. La experiencia reciente de las crisis asiáticas y la anterior crisis del peso mexicano lo confirman. Las asimetrías de información son particularmente serias en los mercados internacionales de capital. Estas asimetrías llevan a que los cambios en las percepciones de los agentes financieros sean mucho mayores que los cambios en las variables fundamentales de las economías en la cual invierten. Agregándose a esto el "efecto manada" que implica que los inversionistas se mueven para su mayor seguridad individual en forma conjunta para entrar y salir de las distintas economías. A consecuencia de ello, los flujos de capitales hacia los países emergentes tiendan a ser muy volátiles, incluso para economías relativamente bien manejadas y con elevado crecimiento, como las asiáticas.

La existencia de importantes imperfecciones en los mercados de capitales internacionales justifica claramente dos tipos de medidas. Por una parte, implica la necesidad de una ampliación importante de los recursos del Fondo Monetario Internacional, para que éste pueda jugar efectivamente su rol de prestamista internacional de última instancia, y así reducir los efectos dañinos de crisis cambiarias y financieras de tamaño importante en países individuales y que el contagio las difunda a otros países emergentes.

Por otra parte, se debe evitar que las actividades del Fondo Monetario Internacional como un prestamista de última instancia internacional lleven a un problema de "riesgo moral", es decir a que los inversionistas y prestamistas privados internacionales asuman riesgos excesivos, sabiendo que serán rescatados si la situación se vuelve crítica. Por ello, en caso de crisis, los prestamistas privados deben contribuir a su superación, renovando sus préstamos a vencer sin exigir aumentos en los intereses ni garantías estatales, de modo que los recursos de las instituciones financieras internacionales y de los gobiernos financien la recuperación de las economías en crisis, y no el pago de deudas anteriores. Naturalmente, lo ideal es evitar que la crisis ocurra. La mejor manera de evitarla es tomar acciones, a nivel internacional, durante los períodos de excesivo optimismo, para moderar el ciclo de los flujos de capitales hacia los países emergentes, y hacer así que dichos flujos sean más sostenibles.

Es por ello importante mejorar y sobre todo completar la supervisión prudencial internacional, para adaptarla a las nuevas circunstancias de flujos 
grandes y volátiles. Dos temas aparecen como prioritarios. Por una parte, parece esencial un mejoramiento de la supervisión y regulación prudencial ya existente en los países desarrollados de los créditos internacionales de corto plazo. Por otra parte, parece muy importante cierta regulación prudencial sobre las inversiones de portafolio de los inversionistas institucionales, como los fondos mutuos. Ello se podría lograr, por ejemplo, a través de requerimientos de liquidez variables ligados al promedio ponderado del riesgo país de las inversiones de portafolio en países en desarrollo de instituciones como los fondos mutuos. La evaluación de riesgo variaría para los diferentes países emergentes, y se modificaría en forma periódica, de acuerdo a la evolución de los riesgos macroeconómicos. Para ello se tomaría en cuenta factores tales como el tamaño del déficit de la cuenta corriente y de los pasivos externos como proporción del PIB, la estructura de plazos de dicha deuda, la fragilidad bancaria del país, y la elevación de precios de acciones más allá de lo que está sustentado en los resultados de las empresas. Dichos requerimientos de liquidez serían aplicados por las Superintendencias de Valores de los países de origen de la oferta de fondos, en consulta con sus Bancos Centrales, con el Fondo Monetario Internacional y con el Banco de Pagos Internacionales. Hay aquí un paralelo con medidas prudenciales de los Bancos Centrales de los países desarrollados, a través de las cuales se exigen provisiones ponderadas por riesgo en contra de pérdidas posibles resultantes de préstamos bancarios a países en desarrollo; los requisitos prudenciales a los inversionistas institucionales seguirían el mismo principio, pero estarían debidamente adaptados a las características institucionales de los fondos mutuos.

Como los requisitos de liquidez variarían con el riesgo macroeconómico percibido, si las variables macroeconómicas comenzaran a deteriorarse en un país, los influjos extranjeros caerían gradualmente, ya que su riesgo ponderado subiría gradualmente, lo que elevaría los requerimientos de liquidez. Ello induciría al país receptor a una corrección temprana de los desequilibrios macroeconómicos. Las fluctuaciones de los flujos serían mucho menores, lo cual haría menos probables crisis cambiarias tan costosas.

Sería posible complementar la supervisión prudencial de los mercados crediticios y de capitales internacionales con una medida tributaria Internacional. Un pequeño impuesto a todas las transacciones en moneda extranjera a nivel mundial actuaría como un desincentivo 
relativamente importante a flujos especulativos de capital de muy corto plazo (que tributarían con mucha frecuencia) y tendrían un impacto muy marginal sobre flujos de largo plazo. Tal impuesto contribuiría a aumentar en algo la autonomía de las autoridades económicas nacionales para hacer política monetaria; además, al disminuir los flujos más volátiles, contribuiría a que los tipos de cambios de los países emergentes reflejaran en mayor proporción las variables fundamentales de largo plazo y en menor proporción cambios fuertes de percepciones de corto plazo de riesgo y rentabilidad. 